Columbia Law School

Scholarship Archive

2006

\title{
Public Preferences for Rehabilitation versus Incarceration of Juvenile Offenders: Evidence from a Contingent Valuation Survey
}

Daniel S. Nagin

Carnegie Mellon University, dn03@andrew.cmu.edu

Alex R. Piquero

University of Florida, apiquero@utdallas.edu

Elizabeth S. Scott

Columbia Law School, escott@law.columbia.edu

Laurence Steinberg

Temple University Department of Psychology, Ids@temple.edu

Follow this and additional works at: https://scholarship.law.columbia.edu/faculty_scholarship

Part of the Criminal Law Commons, and the Juvenile Law Commons

\section{Recommended Citation}

Daniel S. Nagin, Alex R. Piquero, Elizabeth S. Scott \& Laurence Steinberg, Public Preferences for

Rehabilitation versus Incarceration of Juvenile Offenders: Evidence from a Contingent Valuation Survey, 5 CRIMINology \& PuB. PoL'Y 627 (2006).

Available at: https://scholarship.law.columbia.edu/faculty_scholarship/2493

This Article is brought to you for free and open access by the Faculty Publications at Scholarship Archive. It has been accepted for inclusion in Faculty Scholarship by an authorized administrator of Scholarship Archive. For more information, please contact scholarshiparchive@law.columbia.edu. 


\title{
PUBLIC PREFERENCES FOR \\ REHABILITATION VERSUS \\ INCARCERATION OF JUVENILE \\ OFFENDERS: EVIDENCE FROM A \\ CONTINGENT VALUATION SURVEY*
}

\author{
DANIEL S. NAGIN \\ Carnegie Mellon University
}

\author{
ALEX R. PIQUERO \\ University of Florida \\ ELIZABETH S. SCOTT \\ Columbia University \\ LAURENCE STEINBERG \\ Temple University
}

\begin{abstract}
Research Summary:
Accurately gauging the public's support for alternative responses to juvenile offending is important, because policy makers often justify expenditures for punitive juvenile justice reforms on the basis of popular demand for tougher policies. In this study, we assess public support for both punitively and nonpunitively oriented juvenile justice policies by measuring respondents' willingness to pay for various policy proposals. We employ a methodology known as "contingent valuation" $(\mathrm{CV})$ that permits the comparison of respondents' willingness to pay (WTP) for competing policy alternatives. Specifically, we compare CVbased estimates for the public's WTP for two distinctively different responses to serious juvenile crime: incarceration and rehabilitation. An additional focus of our analysis is an examination of the public's WTP for an early childhood prevention program. The analysis indicates that the public is at least as willing to pay for rehabilitation as punishment for juvenile offenders and that WTP for early childhood prevention is also substantial. Implications and future research directions are outlined.
\end{abstract}

* Authors are listed in alphabetical order. This research was supported by the MacArthur Foundation Research Network on Adolescent Development and Juvenile Justice. Address all correspondence to Alex R. Piquero, Department of Criminology, Law \& Society, University of Florida, 201 Walker Hall, P.O. Box 115950, Gainesville, FL. 32611-5950 (e-mail: apiquero@ufl.edu).

VOLUME 5

NUMBER 4

PP 627-652 


\section{Policy Implications:}

The findings suggest that lawmakers should more actively consider policies grounded in rehabilitation, and, perhaps, be slower to advocate for punitive reforms in response to public concern over high-profile juvenile crimes. Additionally, our willingness to pay findings offer encouragement to lawmakers who are uncomfortable with the recent trend toward punitive juvenile justice policies and would like to initiate more moderate reforms. Such lawmakers may be reassured that the public response to such initiatives will not be hostile. Just as importantly, reforms that emphasize leniency and rehabilitation can be justified economically as welfare-enhancing expenditures of public funds. The evidence that the public values rehabilitation more than increased incarceration should be important information to cost-conscious legislators considering how to allocate public funds. Cost-conscious legislatures may become disenchanted with punitive juvenile justice policies on economic grounds and pursue policies that place greater emphasis on rehabilitation. They may be reassured, on the basis of our findings, that the public will support this move.

KEYWORDS: Public Opinion, Punishment, Rehabilitation, Juvenile Justice, Prevention, Crime Policy

Over the past few decades, American juvenile justice policy has become progressively more punitive, as evidenced by the increasingly harsh nature of the dispositions imposed on juveniles who have been adjudicated delinquent or guilty, as well as by the marked increase in the number of states in which juveniles can be tried as adults (Bishop, 2000; Scott and Steinberg, 2003). During the 1990s, in particular, legislatures across the country enacted statutes under which growing numbers of youths can be prosecuted in criminal courts and sentenced to prison (Reppucci, 1999; Scott, 2000; Snyder and Sickmund, 1995). Indeed, today, in almost every state, youths who are 13 or 14 years of age (or less) can be tried and punished as adults for a broad range of offenses, including nonviolent crimes (Griffin et al., 1998; Sickmund, 2003). Even within the juvenile system, punishments have grown increasingly severe (Bishop, 2000; Fagan and Zimring, 2000).

It is generally accepted that intense public concern about the threat of youth crime has driven this trend, and that the public supports this legislative inclination toward increased punitiveness (Roberts, 2004). And yet, it is not clear whether this view of the public's attitude about the appropriate 
response to juvenile crime is accurate. On the one hand, various opinion surveys have found public support generally for getting tougher on juvenile crime and punishing youths as harshly as their adult counterparts (Bureau of Justice Statistics [BJS] Sourcebook, 2003; Moore, 1994; Soler, 2001). At the same time, however, scrutiny of the sources of information about public opinion reveals that the view that the public supports adult punishment of juveniles is based largely on either responses to highly publicized crimes such as school shootings or on mass opinion polls that typically ask a few simplistic questions (Cullen et al., 2000; Roberts and Stalans, 1997). Moreover, evidence from recent research that seeks to probe more deeply into adults' attitudes toward juvenile crime suggests that the public response may be more complex than political rhetoric suggests (Roberts et al., 2003; Schiraldi and Soler, 1998; Stalans and Henry, 1994). For example, several surveys have found public support for rehabilitation as a goal of juvenile justice policy (Moon et al., 2000; Roberts, 2004) and for sanctions and programs that are alternatives to prison (Krisberg and Austin, 1993). One survey found that participants thought that school discipline, rather than imprisonment, was the best way to reduce juvenile crime (Hough and Roberts, 2003). It is plausible that assessments of public sentiment about juvenile crime, and the appropriate response to it, vary greatly as a function of when and how public opinion is gauged.

An assessment of the public's support for various responses to juvenile offending is important because policy makers often justify expenditures for punitive juvenile justice reforms on the basis of popular demand for tougher policies. Punitive responses to juvenile crime (e.g., the incarceration of juvenile offenders in correctional facilities) are far more expensive than less harsh alternatives (e.g., providing juvenile offenders rehabilitative services in community settings). Furthermore, there is little evidence that these more punitive policies are more effective in deterring future criminal activity, and some evidence (Bishop et al., 1996) that overly punitive responses, such as the incarceration of juvenile offenders in adult facilities, actually may increase juvenile offending (Fagan, 1997). If politicians' misreading of public sentiment has led to the adoption of more expensive policy alternatives than the public actually wants, tax dollars are likely being wasted on policies that are costly and possibly ineffective, and that may be less popular than is widely assumed.

In this study, we assess public opinion toward juvenile justice policy using an approach that differs from conventional polling, by measuring respondents' willingness to pay (WTP) for various policy proposals. We employ a methodology known as "contingent valuation" (CV), which permits the comparison of respondents' willingness to pay for competing policy alternatives. In our judgment, this approach has three principal advantages over conventional public opinion polling. 
First, asking how much respondents as individual taxpayers are willing to pay for a specific policy likely yields a more accurate estimate of their attitude toward that policy than merely asking whether they approve or disapprove of it, because the question requires the respondent to consider the cost of the policy as well as its benefits. One of the shortcomings of most public opinion polling about policy options is that the questions posed seldom situate the hypothetical alternatives in a concrete economic context. It is far easier to endorse a particular policy when it is proposed in the abstract (e.g., "Do you favor expanding the city's sanitation services in order to clean the streets more frequently?") than when one is told the actual cost of that policy (e.g., "Do you favor expanding the city's sanitation services in order to clean the streets more frequently, at an annual cost to the city of $\$ 1$ million per year?") or what the impact of that policy would be on the respondent's personal tax burden ("Would you be willing to pay an additional $\$ 100$ in property taxes annually in order to expand the city's sanitation services and clean the streets more frequently?"). As a consequence, conventional polls may indicate more enthusiastic public support for a potentially expensive policy than would likely be the case if the actual cost burden of the policy were revealed. Although asking a respondent how much he or she would be willing to pay for a given program or intervention is not the same as a formal referendum in which respondents are asked to vote up or down a policy where the cost to the individual taxpayer is specified in advance, the approach employed in the current study likely yields a more accurate estimation of public opinion than does conventional polling.

Second, the CV methodology employed here permits a more direct comparison of public attitudes toward different policies designed to address the same fundamental problem. In conventional opinion polling, respondents' preference for one versus another policy is often ascertained (e.g., "Do you favor Policy A or would you prefer Policy B?"), but the phrasing of such comparative questions seldom provides respondents with information on the relative effectiveness or cost of the proposed options. Without knowing what the respondent believes to be the effectiveness or cost of each alternative, one is unable to know what the respondent's answer genuinely reflects. Imagine, for example, how different one's responses to a question contrasting Policy A and Policy B might be if one were told that the first option had been shown to be only half as effective as the second, or that the second cost five times as much as the first. In the current study, we use an experimental methodology that permits us to compare respondents' opinions about policy alternatives that are presented as equally effective. Any observed differences in respondents' willingness to pay for two policies of equal effectiveness must necessarily indicate a true preference for one over the other. 
The third advantage of the CV methodology is that it permits one to calculate a rough estimate of the economic value of a given policy to the public. Generally speaking, crime policy is seldom formulated on the basis of careful assessments of the economic costs and benefits of different policy options or by taking into account their relative value to the public (Cook and Ludwig, 2000; Nagin, 2001; Zimring and Hawkins, 1995). Increasingly, however, legislators want to know whether the economic benefits, measured in dollar terms, of a given policy outweigh its actual costs. But whereas estimating the costs of a given crime policy (e.g., mandating that correctional facilities provide drug treatment for individuals with drug abuse or dependency problems) is often possible (i.e., one can multiply the actual cost of providing treatment by the number of inmates with drug problems), estimating the economic benefits of the same policy is a different matter, because many such benefits are intangible (e.g., increases in the public's feelings of safety), and assigning a monetary value is difficult. As a consequence, it is often impossible to compute a cost-benefit ratio for various policy alternatives based on an assessment of the tangible benefits of the policy.

The CV methodology overcomes this problem by estimating the economic value of various policies in the most straightforward way possible: by determining how much individuals are willing to pay for each of them. This approach differs from conventional economic analyses that focus solely on the tangible benefits of interventions (e.g., estimates of the number of days of added employment one could gain by successfully treating individuals with drug addiction) because it permits the assessment of intangibles that are difficult to value economically but that are nevertheless important in the overall assessment of the value of an intervention (e.g., the added safety that individuals feel knowing that fewer individuals with drug problems are living in their neighborhood). The $\mathrm{CV}$ approach finesses the difficulties inherent in trying to build an estimate of total benefits by estimating WTP for each of the component benefits by asking respondents for WTP for total package of benefits that may attend a particular policy. Thus, if the average taxpayer in a given state is willing to pay an additional $\$ 100$ in taxes each year to implement a particular policy, 1 and there are 5 million taxpayers in that state, the annual value of that policy to the taxpayers in that state is $\$ 500$ million based on the WTP criterion. A comparison of this figure with the known cost of the policy produces a rough calculation of its cost-benefit ratio and, if multiple policies are studied, their relative cost-benefit ratios. Thus, a policy promises

1. Of course, because there is no real measure of the value of various policies, what is available are public perception data. 
to offer substantial value if the public is willing to pay more than its actual cost.

The CV methodology has been widely used in the study of other policy arenas (Mitchell and Carson, 1989), but only recently has it been used in the criminal justice context to estimate the value of crime-control programs in general (Cohen et al., 2004), the value of violent crime prevention (Atkinson et al., 2005), and such interventions as drug abuse treatment programs (Zarkin et al., 2000) and gun control policies (Cook and Ludwig, 2000; Ludwig and Cook, 2001) in particular.

The current study employs a CV methodology to compare public attitudes toward two distinctively different responses to serious juvenile crime: incarceration and rehabilitation. The study was carried out in Pennsylvania, a state that is a mixture of urban, suburban, and rural communities and that is fairly representative of the U.S. population with respect to its political climate (in the 2000 Presidential election, Pennsylvanians, like the country as a whole, split nearly evenly between Bush and Gore). Importantly, however, Pennsylvania's crime rates differ significantly from those in other parts of the country in ways that might make residents more punitive in their preferred response to violent crime. Although Pennsylvania has one of the lowest rates of juvenile property crime in the country $(1,222$ per 100,000 population, compared with the U.S. average of 1,442 per 100,000 ), its rate of violent juvenile crime is among the highest in the nation (402 per 100,000 in Pennsylvania, compared with the U.S. average of 291 per 100,000$)$.

\section{DATA AND METHODS}

Telephone interviews were conducted with a random sample of Pennsylvania households (adults over the age of 18) between March 2005 and August 2005. Individuals, in either English or Spanish, were selected as respondents within each household according to the following script based on the random sample selection procedure:

Hello, my name is _. I'm calling from the University of Florida. This is not a sales call. We are conducting academic research about crime in Pennsylvania. This research is being conducted by the University of Florida in collaboration with Temple University and we would like your opinion. First, I need to know if you are (under 18 years old or) 18 years old or older. If not, may I speak to someone 18 years old or older who lives there? According to the research method being used by the University, I have to ask some questions of the ADULT (age 18 or older) who had the most recent birthday who currently resides there. Your phone number was selected at random by computer, and only your first name will be used to insure confidentiality. You do not 
have to answer any question you do not wish to answer. I also want you to know that this call may be recorded for quality control purposes. It should take only 7-10 minutes. May I have your first name?

The survey followed this brief introduction.

A random digit dial was conducted with an original sample of 7,570 telephone numbers. Of these, 4,231 were ineligible (business/government, fax, etc., $\mathrm{n}=3,390$; language or mental inability, $\mathbf{n}=84$; answering machine, $\mathrm{n}$ $=748$; and respondent never available, $n=9$ ), leaving an eligible sample of 3,339 . Of these eligible numbers, 1,837 refused leaving a completed sample of 1,502 . Thus, the response rate, out of the eligible number of 3,339 , is given by $1,502 / 3,339$, or $44.98 \%$, and it is comparable with that reported in other similar contingent valuation studies (see Cohen et al., 2004). With respect to race and sex, the sample closely mirrored the state's population. Specifically, $86.7 \%$ of the sample was white, and $59.7 \%$ of the sample was female; according to 2000 census data, $85.4 \%$ of the state's population is white and $51.7 \%$ female. Fifty-percent of the study sample reported an income over $\$ 50,000$, and $50 \%$ reported at least some college experience, again comparable with the state as a whole. The average age of the respondents was 50.18 (range 18-94; median 50).

A survey was developed to examine respondents' WTP for rehabilitation and incarceration of juvenile offenders. The survey instrument was drafted using an extensive design process that also included pretesting among young adults. Additionally, we followed the guidelines established by the National Oceanic and Atmospheric Administration (NOAA) for studies employing the contingent valuation methodology, and we modeled our approach after prior contingent valuation research in criminology more specifically (Cohen et al., 2004; Ludwig and Cook, 2001). The average time to complete the survey was just under nine minutes.

Respondents were presented with several hypothetical scenarios and numerous questions about their background and attitudes. The basic survey was the same for all individuals, with one important exception. One item, which asked respondents if they would be willing to vote for a crime policy proposal requiring each household to pay an additional amount of money in taxes, was systematically varied. Half of the sample, randomly selected, responded to a proposal to increase the amount of rehabilitative services provided to violent juvenile offenders, without any increase in their time incarcerated, whereas the other half of the sample responded to a proposal to increase the amount of time violent juvenile offenders were incarcerated for their crime, without the addition of any services. Otherwise, the wording of the two proposals was nearly identical, in order to compare responses to each of them.

The text of the added rehabilitation question was as follows: 
Currently in Pennsylvania, juvenile offenders who commit serious crimes such as robbery are put in jail for about one year. Suppose Pennsylvania citizens were asked to approve the addition of a rehabilitation program to the sentence for these sorts of crimes. Similar programs have reduced youth crime by $30 \%$. Youths in these programs are also more likely to graduate from high school and get jobs. If the change is approved, this new law would cost your household an additional $\$ 100$ per year in taxes. ${ }^{2}$

After reading this question, respondents were asked: "Would you be willing to pay the additional $\$ 100$ in taxes for this change in the law?" Respondents who indicated "yes" were asked an additional follow-up question: "Would you be willing to pay $\$ 200$ for the same change?" Respondents who indicated "no" to the original question also were asked an additional follow-up question: "Would you be willing to pay an additional $\$ 50$ for this change?" Response options to all questions were "Yes" and "No."

The text of the added incarceration question was nearly identical:

Currently, in Pennsylvania juvenile offenders who commit serious crimes such as robbery are put in jail for about one year. Suppose Pennsylvanians were asked to vote on a change in the law that would increase the sentence for these sorts of crimes by one additional year, making the average length of jail time two years. The additional year will not only impose more punishment but also reduce youth crime by about $30 \%$ by keeping juvenile offenders off the street for another year. If the change is approved, this new law would cost your household an additional $\$ 100$ per year in taxes. 3

2. The $30 \%$ crime reduction figure was obtained from Lipsey's (1992) meta-analysis findings regarding the effect of rehabilitation.

3. Three other points regarding the scenarios are in order. First, we retained the $30 \%$ crime reduction estimate and the $\$ 100$ dollar amount so as to maintain rough comparability with the rehabilitation-added scenario presented to the other half of the sample. Second, the rehabilitation-added scenario also suggests that employment and educational benefits may result from the expenditure, benefits that do not follow from additional incarceration. This statement is based on research findings that indicate that rehabilitation programs often provide additional non-crime benefits (Cullen and Gendreau, 2000). In our discussion of the findings, we examine the implications of the difference between the two scenarios. Third, two small matters might bias the WTP between punishment and rehabilitation. With regard to the rehabilitation scenario, the respondents are asked to consider a proposal to approve the addition of a rehabilitation sentence for particular sorts of crimes. They are not specifically told that the incarceration time would not increase. It seems possible, therefore, that at least some respondents interpreted "addition" to mean extended supervision of some sort (i.e., a longer sentence) under which a treatment program would be provided. Thus, for these respondents, rehabilitation and additional punishment would be at least somewhat conflated. 
The same follow-up questions were asked of respondents who received the incarceration scenario as were asked of respondents who were presented with the rehabilitation scenario.

Many other questions in the survey were included to validate respondents' answers to the WTP question. For instance, to gauge their overall preference for punitive responses to juvenile crime, all respondents were presented with the following question:

Jason, who is 15 years old, is convicted of robbing a convenience store. While a gun was used, nobody was injured. Jason has no history of arrests for violent crimes but has been previously arrested for stealing. Do you think Jason should be sent to jail?

Respondents who indicated that Jason should be sent to jail were presented with a follow-up question about how long, in years, they believed Jason's sentence should be.

Similarly, all respondents were presented with one scenario designed to gauge their interest in spending additional tax dollars for an early childhood prevention program modeled after a nurse home visitation program developed by Olds et al. (1998). The text of the question reads as follows:

The state of Pennsylvania is considering starting a program of home visits by nurses to young mothers in which nurses encourage healthy behaviors during pregnancy, good parenting, and the mother's own personal development in terms of education and work. This program has been found to reduce the child's later involvement in crime and also cut their use of alcohol during adolescence. In addition, it cuts welfare use of the women themselves and reduces the chances of their abusing their children. Would you be willing to pay the additional $\$ 150$ in taxes for this change in the law? 4

As with the other WTP question, follow-up questions were asked depending on the respondent's initial response. Respondents who indicated "yes" were asked: "Would you be willing to pay $\$ 300$ for the same change?" Respondents who indicated "no" to the original question were asked: "Would you be willing to pay an additional $\$ 75$ for this change?"

Second, and suggesting a bias in the opposite direction, the effectiveness of the punishment policy may be overstated. The extension of sentences by one year would be applied to all. Thus, we are not talking about selective incapacitation. Our goal was to hold the effectiveness of the hypothetical policy constant across the two versions of the survey, even though there is evidence that rehabilitation outstrips punishment programs in reducing recidivism. We would like to thank a reviewer for pointing this out.

4. These were all findings reported in the Olds et al. (1998) evaluation. 


\section{RESULTS}

\section{WTP ESTIMATES}

Table 1 arrays WTP by four bid levels: (1) those who said no to $\$ 100$ and no to $\$ 50$ (to be conservative in our estimate of WTP, coded $\$ 0$ ); (2) those who said yes to $\$ 50$ but no to $\$ 100$ (coded $\$ 50$ ); (3) those who said yes to $\$ 100$ but no to $\$ 200$ (coded $\$ 100$ ); and (4) those who said yes to $\$ 100$ and yes to $\$ 200$ (coded $\$ 200$ ). 5

\section{TABLE 1. WTP AT BID LEVELS BY CONDITION}

\begin{tabular}{lccc}
\hline Bid & Rehab & Punish & Nurse Visit \\
\hline No 50-No 100 & $27.8 \%$ & $40.8 \%$ & \\
Yes 50-No 100 & $6.9 \%$ & $7.4 \%$ & \\
Yes 100-No 200 & $36.0 \%$ & $26.3 \%$ & \\
Yes 100-Yes 200 & $29.4 \%$ & $25.5 \%$ & \\
No 75-No 150 & & & $35.0 \%$ \\
Yes 75-No 150 & & & $8.4 \%$ \\
Yes 150-No 300 & & & $33.7 \%$ \\
Yes 150-Yes 300 & & $\$ 80.97$ & $23.0 \%$ \\
Average WTP & $\$ 98.10$ & 699 & 125.71 \\
Number of & 712 & & 1442 \\
respondents & & & \\
\hline
\end{tabular}

With regard to the rehabilitation-added scenario, $27.8 \%$ of the respondents were unwilling to pay for the service, whereas the rest were willing to pay at least $\$ 50$. As shown, over $60 \%$ of the respondents who received the rehabilitation-added scenario were willing to pay at least $\$ 100$ for the program. With regard to the punishment-added scenario, $40.8 \%$ of the respondents were unwilling to pay for the service, a much higher percentage compared with the rehabilitation-added scenario and a difference that is significant at $p<0.01$. Also, a little over $50 \%$ of the respondents who received the punishment-added scenario were willing to pay at least $\$ 100$ for the program. As for the nurse home visitation program, $65 \%$ of

5. It is important to note here that these amounts may underestimate some participants' willingness to pay for rehabilitation or punishment. Presumably, there are people who would spend more than $\$ 200$ (the highest figure we offer as an option for the rehabilitation and punishment scenarios) and there are people who might spend somewhere between $\$ 0$ and $\$ 50$ (we score anyone who says "no" to $\$ 50$ as being willing to spend nothing). Thus, the estimates are conservative because we only know that respondents would be willing to pay "at least" XX dollars. Other approaches could use the midpoint as a WTP. 
respondents were willing to pay at least $\$ 75$ for the program and $56.7 \%$ were willing to pay $\$ 150$ or more for the program.

Perhaps the most interesting finding from Table 1 concerns the average WTP for the rehabilitation-added and punishment-added scenarios. Here it can be seen that the average WTP was almost $\$ 20$ higher for the addition of rehabilitation services, $\$ 98.10 /$ household, than for the addition of an extra year of incarceration, $\$ 80.97$. This difference is significant at $p<$ 0.01 . It is also noteworthy that the average WTP is still higher for the nurse visitation program, $\$ 125.71$, although the different response metric used for this scenario cautions against a direct comparison with the other two.

Further analysis indicated that African-American participants were more willing to pay for rehabilitation than whites (\$102.35 vs. \$97.52) and less willing to pay for incarceration $(\$ 59.31$ vs. $\$ 84.67)$. Women were more willing to pay for rehabilitation than were men (\$102.01 vs. \$92.39). WTP for both rehabilitation and incarceration generally increased with income, as economic theory (Viran, 1992) would predict. For example, for households with income greater than $\$ 100,000$ average WTP for rehabilitation is $\$ 124.65$, whereas for households with income less than $\$ 25,000$, it is $\$ 85.56$. This correlation between income and WTP increases our confidence that expressed WTP is a reflection of real preferences.

Several other findings also increase our confidence that the responses to the hypothetical contingent valuation scenarios were based on actual preferences. We expected that compared with conservatives and more punitively oriented respondents, liberals and less punitively oriented respondents would be more supportive of rehabilitation and less supportive of punishment. This is precisely what we found. Support for rehabilitation was stronger among participants who identified themselves as liberal than among those who identified themselves as conservative ( $\$ 131.47$ vs. $\$ 84.11$ ). Not surprisingly, differences were also found between those who favored a noncustodial response to the vignette asking the appropriate disposition for the youth who committed an armed robbery over those who favored prison. Respondents who recommended a prison sentence reported significantly higher average WTP for punishment than respondents who recommended a noncustodial sentence, $\$ 98.16$ vs. $\$ 46.83$, and significantly lower average WTP for rehabilitation, $\$ 94.25$ vs. $\$ 111.29$. Finally, respondents who believe that sending juveniles to jail is more effective than rehabilitation have higher WTP for jail than respondents with the converse expectations, $\$ 88.90$ vs. $\$ 72.71$, and comparatively lower WTP for rehabilitation, $\$ 81.85$ vs. $\$ 110.02 .6$

6. With the exception of the white/black difference in WTP for rehabilitation, all 
Although respondents differ in their responses depending on their political philosophy and attitudes toward punishment, our results suggest broad public support for effective rehabilitation. Even more punitively oriented respondents expressed substantial WTP for rehabilitation. Similarly, although self-identified conservatives reported significantly higher WTP for punishment than self-identified liberals, $\$ 86.29$ vs. $\$ 62.76$, and significantly lower WTP for rehabilitation, conservatives as well as liberals expressed substantial support for public investment in effective rehabilitation.

\section{COST-BENEFIT ANALYSIS}

In this section, we use the results of the contingent valuation survey to conduct a "first-cut" cost-benefit analysis. We caution against placing too great a weight on the specific calculations because participants in our survey responded to a hypothetical question; nonetheless, we believe the cost-benefit analysis is informative, particularly regarding the important question for juvenile justice policy of striking the right balance between the punishment and rehabilitation of offenders (e.g., Moon et al., 2000), and for correctional policy decision makers who are faced with the task of allocating scarce financial resources (Caldwell et al., 2006).

Dollar cost estimates provide a useful means of comparing different types of crime prevention efforts and "reasonable minds can and do differ over how best to conduct cost-benefit analyses of [correctional] policies, how best to implement the results of such analyses, and how, if at all, to fashion or re-orient public policies accordingly" (Dilulio, 1990:51). As do others, we recognize that the comparison of the benefits and costs of alternative crime-control policies is controversial, but nevertheless useful and important. One advantage of cost-benefit analysis and its use of dollars as a common metric for analyzing criminal justice policy is that society spends dollars to try to prevent crimes (Cohen, 2005:6). The key question, of course, is whether the reduced (increased) crime as a function of different crime-control policies is worth its cost. Cohen has convincingly argued that a compelling reason to attempt a cost-benefit analysis is the consequence of not doing so (pp. 6-7):

Whenever a criminal justice or prevention program is adopted or not adopted, society is implicitly conducting a benefit-cost analysis and placing dollar values on crimes. For example, suppose one program costs $\$ 1$ million and ultimately will prevent 100 burglaries from occurring. Whether made explicit or not, the policymaker adopting that program has determined that it is worth spending at least $\$ 10,000$ to reduce each burglary ( $\$ 1$

the differences reported in this paragraph and the prior paragraph are significant at the $p<.01$ level. 
million divided by 100 burglaries). If another $\$ 1$ million program that was not funded would have prevented 50 serious physical assaults from occurring, the policymaker is implicitly determining that each assault is worth less than $\$ 20,000$ ( $\$ 1$ million divided by 50 ). Thus even the policymaker who has ethical concerns about placing dollar values on crime and conducting benefit-cost analysis implicitly makes a value judgment about the monetary value of crime.

In short, although cost-benefit analysis does have its limitations, which we recognize and admit, we nevertheless believe that the information gleaned from such an exercise is a useful piece of knowledge.

The estimates of WTP for incarceration, rehabilitation, and early prevention at the level of the household provide the basis for calculating statewide WTP for each of these programs. According to the 2000 U.S. Census, there were 4.78 million households in Pennsylvania. Based on this scale factor, Table 2 translates our contingent valuation-based estimates of average WTP per household into statewide WTP. We should note again that the WTP estimates for the nurse visitation program cannot be directly compared with those for the other two scenarios, because the response options were not the same.

\section{TABLE 2. PROGRAMS BENEFITS}

\begin{tabular}{lcc}
\hline Program & $\begin{array}{c}\text { Ave. WTP per } \\
\text { household per year }\end{array}$ & $\begin{array}{c}\text { Statewide WTP } \\
\text { per year }\end{array}$ \\
\hline Rehabilitation & $\$ 98.1$ & $\$ 468 \mathrm{mil}$. \\
Longer sentence & $\$ 80.97$ & $\$ 387 \mathrm{mil}$. \\
Nurse visitation & $\$ 125.71$ & $\$ 601 \mathrm{mil}$. \\
\hline
\end{tabular}

In the nomenclature of cost-benefit analysis, statewide WTP measures the total dollar value of the benefits of these programs as perceived by a representative sample of Pennsylvanians. The contingent value methodology is not designed to provide an accounting of the relative contributions of various types of perceived benefits of rehabilitation or incarceration that contribute to respondents' WTP. Given the respondents willingness to pay more for the same reduction in crime achieved via rehabilitation as that achieved through incarceration, it seems safe to presume that even if crime reduction is the largest perceived benefit of rehabilitation, other types of benefits such as social productivity of increased employment and individual welfare of affected youths likely contribute as well. In the case of the longer sentence scenario, respondents likely valued retribution and increased public protection in the longer period of incarceration.

The second key ingredient to a cost-benefit analysis is cost estimation. 
Total annual cost is calculated by multiplying an estimate of the annual cost per individual in the target population by an estimate of size of the target population. Table 3 reports this calculation for each program type.

TABLE 3. PROGRAM COSTS

\begin{tabular}{lccr}
\hline Program & $\begin{array}{c}\text { Ave. Cost per } \\
\text { Person-Year }\end{array}$ & $\begin{array}{c}\text { Size of Target } \\
\text { Population }\end{array}$ & Total Cost \\
\hline Rehabilitation & $\$ 10,000$ & 2,000 & $\$ 20 \mathrm{mil}$. \\
Longer sentence & $\$ 50,000$ & 2,000 & $\$ 100 \mathrm{mil}$. \\
Nurse visitation & $\$ 3,000$ & 100,000 & $\$ 300 \mathrm{mil}$. \\
\hline
\end{tabular}

Consider first the estimates of the annual cost per person. A 2003 study by the Washington State Institute for Public Policy reports the cost of a great variety of treatment programs for juvenile offender programs (Aos et al., 2004). The costs vary widely. The three most expensive rehabilitation programs are multisystemic therapy $(\$ 5,681)$, mentoring in the Juvenile Justice System $(\$ 6,471)$, and Intensive Parole $(\$ 5,992)$. To be conservative in our estimation of the benefits of rehabilitation relative to cost, we use what we believe is a high-end cost annual estimate of $\$ 10,000$ per person. A bulletin from Pennsylvania's Department of Public Welfare (2004) reports per diem rates for confinement in various types of secure facilities for juveniles. The average for 2004 was $\$ 306 /$ day, which translates into an annual cost of $\$ 111,000$. Here again we err on the side of caution, but in this case, to avoid overstating the benefit-to-cost ratio of rehabilitation relative to incarceration, we use an annual cost estimate of $\$ 50,000$ per juvenile. The Washington State study reports that the total cost of the Olds' Nurse Family Partnership for Low Income Mothers is $\$ 9,118$ per child. This cost covers about three years of service, the nine months of pregnancy plus two years of follow-up. Therefore, we base our annualized cost calculation on an estimate of $\$ 3000 /$ year per child.

We turn now to our estimates of the size of the target population of youths who would receive added rehabilitation or punishment. Pennsylvania does not report data on the number of juveniles who are incarcerated for committing serious violent crimes of the type, robbery, which was the subject of our WTP scenarios on lengthened sentences and rehabilitation. In 2003, Pennsylvania juvenile courts placed 5,701 juveniles in facilities outside their home (Pennsylvania Juvenile Court Judge's Commission, 2003). However, most of these placements were not to prison-like facilities. For example, 506 were placed in facilities for drug and alcohol treatment and 806 were placed in group-homes. Placement in secure facilities and boot camps probably comes closest to the dispositions received by our 
target population. In 2003, these totaled 1,234. Another 642 were "wilderness-based" placements. Again to be conservative in our estimation of benefit-to-cost ratios, we assumed 2,000 individuals per year would be the targets of the enhanced sentence and rehabilitation programs.

As for the nurse visitation program, census data for Pennsylvania indicate that about 75,000 children two years old or younger live in households below the poverty line. This statistic suggests that 35,000 low-income Pennsylvania women are pregnant each year. We, thus, estimate that with a $100 \%$ participation rate, about 100,000 children, either born or in utero, would be enrolled in the nurse visitation program. A $100 \%$ take-up rate is, of course, unrealistic. However, if we were to use a lower rate, it would seem only reasonable to factor down the estimated benefits by the same factor. As a result, the cost-to-benefit ratio would be unaffected.

Combining the benefits and costs in Tables 2 and 3 yields very different benefit-to-cost ratios by program type. For the rehabilitation option, the ratio of benefits to costs is $23.4(=\$ 468 / \$ 20)$. For the lengthened incarceration option, the ratio is $3.87(=\$ 387 / \$ 100)$, and for the nurse visitation option, the ratio is 2.00 . All imply that benefits as measured by WTP substantially exceed costs. However, the estimated returns per dollar spent differ substantially.

For our purposes here, the difference in return between incarceration and rehabilitation is of particular interest. Both imply very large returns, but the difference in magnitude between rehabilitation, $\$ 23.4$ in benefit per dollar spent versus $\$ 3.87$ per dollar spent for incarceration is striking. This difference is largely attributable to the differences in cost per person between rehabilitation and imprisonment because the assumed size of the target population is the same in both sets of calculations. In fact, had we used the actual current annual cost of incarcerating a juvenile in Pennsylvania based on per diem figures, which are well over $\$ 100,000$, the benefit-to-cost ratio for incarceration would be more than halved.

We emphasize the pivotal role of cost (per offender) in explaining the difference between the benefit-to-cost ratios for incarceration versus rehabilitation for two reasons. One is that the cost per person-year estimates used in the benefit-to-cost calculations are the least speculative of all components of the calculation. We can have some confidence in the accuracy of the costs described above of various rehabilitation programs and of incarceration of juvenile offenders, and there is no dispute that rehabilitation programs are far less costly than incarceration.

A second reason for the emphasis on cost per person is that our estimates of WTP for punishment and rehabilitation, used to derive our estimate of each policy's benefit, are roughly comparable in magnitude. As a result, the difference in the benefit-to-cost ratio of these two options is mostly attributable to the denominator, cost. We judge this an important 
point because it makes clear that according to our contingent valuation survey, the public is at least as supportive of effective rehabilitation of juveniles as they are of punishment of the juveniles for their crimes. Although we acknowledge that the issue of the relative effectiveness of punishment and rehabilitation in crime control is far from settled, the contingent valuation results provide strong support for the contention that the public is willing to pay for effective rehabilitation, and it resonates well with the finding that more treatment-focused services offer a better cost-benefit than more severity-focused sanctions for delinquent youths (Fass and $\mathrm{Pi}, 2002$ ).

\section{DISCUSSION}

This study surveyed 1,500 randomly selected Pennsylvania adults to elicit their opinions about policies responding to youth crime. The survey employed contingent valuation, an innovative methodology that gauges preferences on the basis of respondents' willingness to pay for public benefits, often through a specified increase in taxes. In our study, the alternative policies of increased incarceration or rehabilitation were presented as having equivalent effectiveness in reducing juvenile crime. Participants were initially asked whether they were willing to pay $\$ 100$ in increased taxes; the amount was doubled or halved depending on whether their response was positive or negative.

We found that respondents on average expressed somewhat greater willingness to pay for rehabilitation (\$98.10) than for longer incarceration $(\$ 80.97)$ of youths charged with serious crimes-and even greater willingness to pay for an early childhood prevention program (\$125.71). These results suggest that the public generally is willing to pay for programs that promise to reduce youth crime-and more willing to support and pay for rehabilitation and prevention programs than for longer periods of incarceration (see also Cullen et al., 1998). To an extent, the additional educational and employment benefits of rehabilitation may account for the greater willingness to pay for rehabilitation than for incarceration. Nonetheless, at a minimum, the study finds comparable support for the two policy responses to juvenile crime.7 It is noteworthy that even individuals who identified themselves as conservative or who supported punitive policies in response to attitude questions and the robbery vignette also indicated substantial WTP for rehabilitation and prevention programs. This suggests that rehabilitation and prevention programs as policy responses

7. It is not possible to evaluate how participants who responded to the rehabilitation scenario valued various benefits, but it seems likely that crime reduction was important. Moreover, the research indicates that rehabilitation, in fact, offers the additional educational and employment benefits. See Footnote 2. 
to youth crime have substantial public support across the political spectrum, while at the same time evincing crime reduction much more costeffectively than harsher punishments (Greenwood, 2006).

Our study also provides information that permits the comparison of rehabilitation and incarceration using cost-benefit analysis, a standard mode of policy analysis that has only recently begun to be used in evaluating criminal justice policies (Caldwell et al., 2006). Based on estimates of the yearly costs per offender of incarceration and of rehabilitation programs, and estimates of the number of young offenders incarcerated in Pennsylvania, we calculated a cost-benefit ratio for incarceration and rehabilitation. This analysis produces strikingly different cost-benefit ratios for these two policies, a difference that is the result of two factors: (1) A year of incarceration is far more expensive than a year of rehabilitation and (2) participants' willingness to pay for the two policies was comparable.

Two related limitations of willingness-to-pay methodology should be emphasized, both of which speak to the amount of confidence we can have in participants' responses-or, put another way, whether the amount participants stated they were willing to pay is a meaningful figure. The first is sometimes described as a demand characteristic or "anchoring." Participants were asked initially whether they would pay $\$ 100$, focusing their attention on that amount as a baseline and, likely, influencing their ultimate responses. If they had first been asked if they were willing to pay $\$ 25$, their ultimate WTP amount and, consequently, the average for their scenario may well have been different. The second limitation, mentioned earlier, is that participants understood that the inquiry was hypothetical. Thus, we cannot be sure that their responses would have been the same in a tax referendum, where their expressed willingness to pay might effect their actual tax obligation. For these reasons, the survey does not demonstrate that Pennsylvanians are ready to pay $\$ 468$ million more for rehabilitation programs or $\$ 387$ million for incarceration. The actual amount they are willing to pay for the program described to them may have been less (or more). 8

Nonetheless, the cost-benefit analysis provides useful information for comparing the publics' willingness to pay for the alternative policies. The factors that might undermine our confidence about the participants'

8. On this score, we did not explore the "reason" that the public would be willing to pay more for one policy over another when they have equivalent crime-reduction benefits. Is it because they believe there are other noncrime benefits such as improved high-school education/productivity; better long-term outcomes that are not captured in the $30 \%$ figure; they feel good about setting a youth on the right course; they dislike incarceration; etc? This is an important avenue for future research. We would like to thank Mark Cohen for this suggestion. 
expressions about willingness to pay likely affect responses to both rehabilitation and incarceration similarly. Importantly, there is no reason to think that anchoring would affect responses differently; if participants were asked initially whether they were willing to pay $\$ 25$ for either incarceration or rehabilitation, the average willingness to pay amount likely would be affected for both options by a comparable amount. What is important in evaluating the two policies is that, although the dollar amount that taxpayers are willing to pay for either policy may be uncertain, participants are willing to pay at least as much for rehabilitationprobably somewhat more-as they are for incarceration. This finding, together with the external evidence that incarceration is substantially more costly than rehabilitation, supports the conclusion that the returns per dollar spent on increasing rehabilitation are a better value than the returns on increasing incarceration even if the benefit (based on the public's willingness to pay) is less than the results indicate (see also Cohen et al., 2006; Greenwood, 2006). In other words, the benefit-to-cost ratio for rehabilitation may be lower than the $\$ 23.4$ benefit per dollar spent calculated on the basis of average WTP of $\$ 98.10$, but our contingent valuation survey suggests it will still be favorable compared with the cost-benefit ratio for incarceration.

Our survey challenges the view held by many politicians and the media that the public opposes rehabilitation and favors incarceration of young offenders. According to conventional wisdom, the driving force behind the punitive reforms in recent years has been the public demand for tough juvenile justice policies, and politicians frequently point to public outrage at violent juvenile crime as justification for sweeping legislative reforms. Moreover, some earlier opinion surveys found public support for policies that punish juveniles as adults and pessimistic views about rehabilitation programs offered by the juvenile system. In contrast, our survey suggests that public attitudes about youth crime policy are more complex. We interpret our results to indicate that members of the public are concerned about youth crime and want to reduce its incidence, but they are ready to support effective rehabilitative programs as a means of accomplishing that end-and indeed favor this response to imposing more punishment through longer sentences (e.g., Applegate et al., 1997). This notion is consistent with findings suggesting that the public is willing to support nonpunitive goals such as rehabilitation sometimes to a greater extent than policy makers may realize (Gottfredson and Taylor, 1984), and it is complementary to Cohen et al.'s (2006) finding that the public would prefer to spend its next tax dollars on at-risk youth programs.

What explains the differences between our findings and the conventional view of public opinion about juvenile crime, including the findings 


\section{PUBLIC PREFERENCES FOR REHABILITATION}

of some earlier surveys? First, our survey was conducted recently, and attitudes may have changed since the 1990s, when some surveys found punitive public attitudes. Juvenile crime rates have declined dramatically over the past 10 years (Blumstein and Wallman, 2000), and the public may realize that the threat has subsided. In general, attitudes (and legal policies) toward youth are protective and paternalistic. Perhaps the public is more likely to express these traditional attitudes when they do not perceive young criminals as a threat.

This suggests another reason that politicians and the media may have distorted impressions about public attitudes and crime. Often public opinion on this issue is gauged when attention is focused on a high-profile violent crime by a juvenile, such as a school shooting. In this context, in part because of intense media coverage, the salience and magnitude of the threat may become distorted in the public imagination. In contrast, the attitudes of our participants were probed in a neutral context. It is plausible that their responses represent more stable policy preferences than those of individuals whose opinion is gauged in the midst of media coverage of a horrendous crime.

\section{POLICY IMPLICATIONS}

Any suggestion that our study may offer lessons for policy formation must first acknowledge the survey's limitations. We have discussed the possible sources of distortion in the willingness to pay amounts. Beyond this, the policy implications of the survey are limited by the fact that it was undertaken in a single state, Pennsylvania. A broader sample from different regions of the country might provide a more accurate measure of public opinion about juvenile crime. Nonetheless, as we discussed, there is good reason to think that Pennsylvania residents are likely to be a relatively good proxy for a national sample in their attitudes on this issue; if anything, relatively more punitive responses might be expected in Pennsylvania, given its relatively higher rate of violent juvenile crime (cf. Baumer et al., 2003).

At a minimum, our findings suggest that lawmakers who are concerned about public opinion should consider policies grounded in rehabilitation and, perhaps, be slower to advocate for punitive reforms in response to public concern over high-profile juvenile crimes. Legislation enacted in this climate institutionalizes public fears that are likely short-lived, and it may result in laws that do not reflect stable public preferences about youth crime policy. Our study suggests that the political risk that lawmakers face in resisting public pressure during times of crisis is not as great as they might surmise. During calmer times, traditional paternalistic attitudes toward juveniles may exert a stronger influence on public opinion-dissipating enthusiasm for punitive policies. 
Our WTP findings offer encouragement to lawmakers who are uncomfortable with the recent trend toward punitive juvenile justice policies and would like to initiate more moderate reforms. First, such lawmakers may be reassured that the public response to such initiatives will not be hostile (e.g., Gottfredson and Taylor, 1984). Just as importantly, reforms that emphasize leniency and rehabilitation can be justified economically as welfare-enhancing expenditures of public funds. Rehabilitative programs are far less costly than incarceration and, often, when informed by the principles of effective intervention, more effective (Cullen and Gendreau, 2000) and less harmful (Clear, 1994). The evidence that the public values rehabilitation more than increased incarceration should be important information to cost-conscious legislators considering how to allocate public funds.

Increasingly cost-benefit analysis is becoming a useful and important policy tool (McDougall et al., 2003) as policy makers seek to maximize the value obtained from tax dollars spent. In the realm of criminal justice policy, cost-benefit analysis is relatively new (Caldwell et al., 2006), but cost concerns have become an increasingly important factor in legal regulation. The high cost of punitive sentencing guidelines has become a consideration in the public debate-long sentences translate into more prison space, more staff, and generally higher operating costs. In the past few years, legislatures in several states have reduced criminal sentences in recognition of the high costs of incarceration (Barkow, 2005). Cost-conscious legislatures may become disenchanted with punitive juvenile justice policies on economic grounds and pursue policies that place greater emphasis on rehabilitation and early childhood prevention. If so, they may be reassured, on the basis of our findings, that the public will support this move.

\section{REFERENCES}

Aos, Steve, Roxanne Lieb, Jim Mayfield, Marna Miller, and Annie Pennucci

2004 Benefits and Costs of Prevention and Early Intervention Programs for Youth. Olympia, Wash.: Washington State Institute for Public Policy.

Applegate, Brandon K., Francis T. Cullen, and Bonnie S. Fisher

1997 Public support for correctional treatment: The continuing appeal of the rehabilitative ideal. The Prison Journal 77:237-258.

Atkinson, Giles, Andrew Healey, and Susana Mourato

2005 Valuing the costs of violent crime: A stated preference approach. Oxford Economic Papers 57:559-585.

Barkow, Rachel E.

2005 Federalism and the politics of sentencing. Columbia Law Review 105:1276. 
Baumer, Eric, Steven F. Messner, and Richard Rosenfeld

2003 Explaining spatial variation in support for capital punishment: A multilevel analysis. American Journal of Sociology 108:844-875.

Bishop, Donna

2000 Juvenile offenders in the adult criminal system. In Michael Tonry (ed.), Crime and Justice: A Review of Research, Volume 27. Chicago, Ill.: University of Chicago Press.

Bishop, Donna, Charles E. Frazier, Lonn Lanza-Kaduce, and Lawrence Winner 1996 The transfer of juveniles to criminal court: Does it make a difference? Crime and Delinquency 42: 171-191.

Blumstein, Alfred and Joel Wallman

2000 The Crime Drop in America. New York: Cambridge University Press.

Bureau of Justice Statistics

2003 Sourcebook of Criminal Justice Statistics. Washington, D.C.: U.S. Department of Justice.

Caldwell, Michael F., Michael Vitacco, and Gregory J. van Rybroek

2006 Are violent delinquents worth treating? A cost-benefit analysis. Journal of Research in Crime and Delinquency 43:148-168.

Clear, Todd

1994 Harm in American Penology: Offenders, Victims, and Their Communities. Albany, N.Y.: State University of New York Press.

Cohen, Mark A.

2005 The Costs of Crime and Justice. London, U.K.: Routledge.

Cohen, Mark A. Roland T. Rust, and Sara Steen

2006 Prevention, crime control, or cash? Public preferences toward criminal justice spending priorities. Justice Quarterly. In press.

Cohen, Mark A., Roland T. Rust, Saran Steen, and Simon T. Tidd

2004 Willingness-to-pay for crime control programs. Criminology 42:89-110.

Cook, Philip J. and Jens Ludwig

2000 Gun Violence: The Real Costs. New York: Oxford University Press.

Cullen, Francis T., Bonnie Fisher, and Brandon K. Applegate

2000 Public opinion about punishment and corrections. In Michael Tonry (ed.), Crime and Justice: A Review of Research, Volume 27. Chicago, Ill: University of Chicago Press.

Cullen, Francis T. and Paul Gendreau

2000 Assessing correctional rehabilitation: Policy, practice, and prospects. In Julie Horney (ed.), Policies, Processes, and Decisions of the Criminal Justice System, Criminal Justice 2000. Washington, D.C.: National Institute of Justice.

Cullen, Francis T. John P. Wright, Shayna Brown, Melissa M. Moon, Michael B. Blankenship, and Brandon K. Applegate

1998 Public support for early intervention programs: Implications for a progressive policy agenda. Crime and Delinquency 44:187-204. 
DiIulio, Jr., John J.

1990 Crime and Punishment in Wisconsin: A Survey of Prisoners and an Analysis of the Net Benefit of Imprisonment in Wisconsin. Wisconsin Research Institute Report. Volume 3, Number 7. Milwaukee, Wisc.

Fagan, Jeffrey

1997 The comparative advantages of juvenile versus criminal court sanctions on recidivism among adolescent felony offenders. Law and Policy 18:77-115.

Fagan, Jeffrey and Franklin E. Zimring, (eds.)

2000 The Changing Borders of Juvenile Justice: Transfer of Adolescents to the Criminal Court. Chicago, Ill.: University of Chicago Press.

Fass, Simon M. and Chung-Ron Pi

2002 Getting tough on juvenile crime: An analysis of costs and benefits.

Journal of Research in Crime and Delinquency 39:363-399.

Gottfredson, Stephen D. and Ralph B. Taylor

1984 Public policy and prison populations: Measuring options about reform. Judicature 68:190-201.

Greenwood, Peter W.

2006 Changing Lives: Delinquency Prevention as Crime-Control Policy. Chicago, Ill.: University of Chicago Press.

Griffin, Patrick, Patricia Torbet, and Linda Szymanski

1998 Trying Juveniles as Adults in Criminal Court: An Analysis of State Transfer Provisions. Washington, D.C.: U.S. Office of Juvenile Justice and Delinquency Prevention.

Hough, Mike and Julian V. Roberts

2003 Institute for Criminal Policy Research Study. London, U.K.: King's College School of Law.

Krisberg, Barry and James Austin

1993 Reinventing Juvenile Justice. Newbury Park, Calif.: Sage.

Lipsey, Mark

1992 Juvenile delinquency treatment: A meta-analytic inquiry into the variability of effects. In Thomas D. Cook, Harris Cooper, David S. Cordray, Heidi Hartmann, Larry V. Hedges, Richard J. Light, Thomas A. Louis, and Frederick Mosteller (eds.), Meta-Analysis for Explanation: A Casebook. New York: Russell Sage Foundation.

Ludwig, Jens and Philip J. Cook

2001 The benefits of reducing gun violence: Evidence from contingentvaluation survey data. The Journal of Risk and Uncertainty 22:207-226.

McDougall, Cynthia, Mark Cohen, Raymond Swaray, and Amanda Perry

2003 The costs and benefits of sentencing: A systematic review. Annals of the American Academy of Political and Social Science 587:160-177.

Mitchell, Robert C. and Richard T. Carson

1989 Using Surveys to Value Public Goods. Washington, D.C.: Resources for the Future.

Moon, Melissa, Jody Sundt, Francis T. Cullen, and John P. Wright

2000 Is child saving dead? Public support for juvenile rehabilitation. Crime and Delinquency 46:38-60. 


\section{PUBLIC PREFERENCES FOR REHABILITATION}

Moore, David W.

1994 Majority advocate death penalty for teenage killers. GallupPoll Monthly (September, pp.2-3).

Nagin, Daniel S.

2001 Costs and benefits of crime prevention. In Michael Tonry (ed.), Crime and Justice: A Review of Research, Volume 28. Chicago, Ill.: University of Chicago Press.

Olds, David L., C. R. Henderson, R. Cole, J. Eckenrode, H. Kitzman, D. Luckey, L. Pettitt, K. Sidora, P. Morris, and J. Powers

1998 Long-term effects of nurse home visitation on children's criminal and antisocial behavior: 15 year follow-up of a randomized control trial. Journal of the American Medical Association 280: 1238-1244.

Pennsylvania Department of Public Welfare

2004 Children, Youth and Families (CYF) Bulletin \#00-02-05 (Per Diem Rates/ Locations of Facilities). Harrisburg, Pa: Department of Public Welfare.

Pennsylvania Juvenile Court Judge's Commission

2003 Pennsylvania Juvenile Court Dispositions, 2003. Harrisburg, Pa: Pennsylvania Juvenile Court Judges Commission.

Repucci, N. Dickon

1999 Adolescent development and juvenile justice. American Journal of Community Psychology 27:307-326.

Roberts, Julian V.

2004 Public opinion and youth justice. In Michael Tonry and Anthony N. Doob (eds.), Crime and Justice: A Review of Research, Volume 31, Youth Crime and Youth Justice, Comparative and Cross-National Perspectives. Chicago, Ill.: University of Chicago Press.

Roberts, Julian V. and Loretta J. Stalans.

1997 Public Opinion, Crime, and Criminal Justice. Boulder, Colo.: Westview.

Roberts, Julian V., Mike Hough, David Indermaur, and Loretta J. Stalans

2003 Penal Populism and Public Opinion: Lessons from Five Countries. Oxford, U.K.: Oxford University Press.

Schiraldi, Vincent and Mark I. Soler

1998 The will of the people? The public's opinion of the violent and repeat juvenile offender act of 1997. Crime and Delinquency 44:590-601.

Scott, Elizabeth S.

2000 The legal construction of adolescence. Hofstra Law Review 29:547-598.

Scott, Elizabeth S. and Laurence Steinberg

2003 Blaming youth. Texas Law Review 81:799-840.

Sickmund, Melissa

2003 Juveniles in Court, 6-10. Washington, D.C.: U.S. Department of Justice.

Soler, Mark $\mathbf{I}$.

2001 Public Opinion on Youth, Crime, and Race: A Guide for Advocates. Retrieved May 30, 2005 on Building Blocks for Youth website: www.buildingblocksforyouth.org. 


\author{
Snyder, Howard and Melissa Sickmund \\ 1995 Juvenile Offenders and Victims: National Report. Washington, D.C.: \\ Office of Juvenile Justice and Delinquency Prevention. \\ Stalans, Loretta J. and Gary T. Henry \\ 1994 Societal views of justice for adolescents accused of murder. Law and \\ Human Behavior 18:675-696. \\ Varian, Hal R. \\ 1992 Microeconomic Analysis, 3rd ed. New York: Norton. \\ Zarkin, Gary A., Sheryl C. Cates, and Mohan V. Bala \\ 2000 Estimating the willingness to pay for drug abuse treatment. Journal of \\ Substantive Abuse Treatment 18:149-159. \\ Zimring, Franklin E. and Gordon Hawkins \\ 1995 Incapacitation: Penal Confinement and the Restraint of Crime. New \\ York: Oxford University Press.
}

Daniel S. Nagin is Teresa and H. John Heinz III Professor of Public Policy and Statistics, Heinz School of Public Policy and Management, Carnegie Mellon University. His research focuses on the evolution of criminal and antisocial behaviors over the life course, the deterrent effect of criminal and non-criminal penalties on illegal behaviors, and the development of statistical methods for analyzing longitudinal data. He is the author of Group-based Modeling of Development (Harvard University Press, 2005).

Alex R. Piquero is Professor of Criminology, Law \& Society and 2005 Magid Term Professor in the College of Liberal Arts \& Sciences at the University of Florida, Member of the National Consortium on Violence Research, and Member of the MacArthur Foundation's Research Network on Adolescent Development and Juvenile Justice. His research interests include criminological theory, criminal careers, and quantitative research methods. He is the author of Key Issues in Criminal Careers Research (Cambridge University Press, 2007). He is recipient of the American Society of Criminology's Cavan Award and its E-Mail Mentor of the Year Award, as well as a Teacher of the Year Award recipient from the College of Arts and Sciences at the University of Florida.

Elizabeth S. Scott is the Harold R. Medina Professor of Law at Columbia Law School. Between 1988 and 2006, she was on the faculty of the University of Virginia School of Law. A 1977 graduate of the University of Virginia School of Law, she served as director of the Forensic Psychiatry Clinic of the University's Institute of Law, Psychiatry, and Public Policy for several years before joining the faculty. Her area of scholarly and teaching interest is juvenile and family law. She has written extensively on juvenile delinquency, marriage, divorce, child custody, and adolescent decision making. Much of her research is interdisciplinary, applying social science research, developmental theory, and behavioral economics to legal policy issues involving children and families. Scott has worked in collaboration with social scientists on both empirical and theoretical research dealing with family issues and has published in both law reviews and in interdisciplinary journals and edited volumes. The American Law Institute recently adopted her proposal offered in a California Law Review article that child custody be allocated on the basis of past parental roles (Pluralism, Parental Preference and Child Custody, 80 CAL. L. REV. 615 (1992). She is a co-author with Ira Ellman and Paul Kurtz of a 


\section{PUBLIC PREFERENCES FOR REHABILITATION}

widely used casebook in Family Law. She is also a co-author (with Walter Wadlington, Charles Whitebread, and Samuel Davis) of a casebook on Children in the Legal System.

Laurence Steinberg is the Distinguished University Professor and Laura $\mathrm{H}$. Carnell Professor of Psychology at Temple University and Director of the John D. and Catherine T. MacArthur Foundation Research Network on Adolescent Development and Juvenile Justice. Dr. Steinberg's research has focused on a range of topics in the study of contemporary adolescence, including parent-adolescent relationships, adolescent employment, high-school reform, and juvenile crime and justice. Dr. Steinberg is a member of the National Academies' Board on Children, Youth, and Families and its Committee on the Science of Adolescent Health and Behavior, and he has been a frequent consultant to state and federal agencies and lawmakers on child labor, secondary education, and juvenile justice policy. 